\title{
Characteristics and Clinical Outcomes of Critically III Cancer Patients Admitted to Korean Intensive Care Units
}

\author{
Soo Jin $\mathrm{Na}^{1 *}$, Tae Sun $\mathrm{Ha}^{2 *}$, Younsuck Koh ${ }^{3}$, Gee Young Suh ${ }^{1,4}$, Shin Ok Koh ${ }^{5}$, Chae-Man Lim ${ }^{3}$, Won-II Choi ${ }^{6}$, \\ Young-Joo Lee ${ }^{7}$, Seok Chan Kim ${ }^{8}$, Gyu Rak Chon ${ }^{9}$, Je Hyeong Kim ${ }^{10}$, Jae Yeol Kim ${ }^{11}$, Jaemin Lim ${ }^{12}$, \\ Sunghoon Park ${ }^{13}$, Ho Cheol Kim ${ }^{14}$, Jin Hwa Lee ${ }^{15}$, Ji Hyun Lee ${ }^{16}$, Jisook Park ${ }^{17}$, Juhee Cho ${ }^{18}$, \\ Kyeongman Jeon ${ }^{1,4}$; Validation of Simplified Acute Physiology Score 3 in Korean Intensive care unit (VSKI) \\ study group, and the Korean Study Group On Respiratory Failure (KOSREF)
}

\begin{abstract}
${ }^{1}$ Department of Critical Care Medicine, Samsung Medical Center, Sungkyunkwan University School of Medicine, Seoul; ${ }^{2}$ Department of Surgery, Soonchunhyang University Bucheon Hospital, Bucheon; ${ }^{3}$ Division of Pulmonary and Critical Care Medicine, Department of Medicine, Asan Medical Center, University of Ulsan College of Medicine, Seoul; ${ }^{4}$ Division of Pulmonary and Critical Care Medicine, Department of Medicine, Samsung Medical Center, Sungkyunkwan University School of Medicine, Seoul; ${ }^{5}$ Department of Anesthesiology and Pain Medicine, Anesthesia and Pain Research Institute, Yonsei University College of Medicine, Seoul; ${ }^{6}$ Division of Pulmonary and Critical Care Medicine, Department of Medicine, Dongsan Hospital, Keimyung University, Daegu, ${ }^{7}$ Department of Anesthesiology and Pain Medicine, Ewha Womans University Mokdong Hospital, Seoul;: Division of Pulmonary and Critical Care Medicine, Department of Medicine, Seoul St. Mary's Hospital, College of Medicine, Catholic University of Korea, Seoul, ${ }^{9}$ Division of Pulmonary and Critical Care Medicine, Department of Medicine, Chungju Hospital, Konkuk University School of Medicine, Chungju; ${ }^{10}$ Department of Critical Care Medicine, Korea University Ansan Hospital, Ansan; ${ }^{11}$ Division of Pulmonary and Critical Care Medicine, Department of Medicine, Chung-Ang University College of Medicine, Seoul; ${ }^{12}$ Division of Pulmonary and Critical Care Medicine, Department of Medicine, Gangneung Asan Hospital, University of Ulsan Medical College of Medicine, Gangneung; ${ }^{13}$ Department of Pulmonary, Allergy and Critical Care Medicine, Hallym University Sacred Heart Hospital, Anyang; ${ }^{14}$ Division of Pulmonary and Critical Care Medicine, Department of Medicine, College of Medicine, Gyeongsang Institute of Health Sciences, Gyeongsang National University, Jinju, ${ }^{15}$ Division of Pulmonary and Critical Care Medicine, Department of Medicine, Ewha Womans University School of Medicine, Seoul; ${ }^{16}$ Division of Pulmonary and Critical Care Medicine, Department of Medicine, CHA Bundang Hospital, CHA University, Seongnam; ${ }^{17}$ Department of Multimedia, Seoul Women's University, Seoul; ${ }^{18}$ Samsung Advanced Institute of Health Science and Technology, Samsung Medical Center, Sungkyunkwan University School of Medicine, Seoul, Korea
\end{abstract}

Background: The objective of this study was to investigate the characteristics and clinical outcomes of critically ill cancer patients admitted to intensive care units (ICUs) in Korea. Methods: This was a retrospective cohort study that analyzed prospective collected data from the Validation of Simplified Acute Physiology Score 3 (SAPS3) in Korean ICU (VSKI) study, which is a nationwide, multicenter, and prospective study that considered 5,063 patients from 22 ICUs in Korea over a period of 7 months. Among them, patients older than 18 years of age who were diagnosed with solid or hematologic malignancies prior to admission to the ICU were included in the present study.

Results: During the study period, a total of 1,762 cancer patients were admitted to the ICUs and 833 of them were deemed eligible for analysis. Six hundred fifty-eight (79\%) had solid tumors and $175(21 \%)$ had hematologic malignancies, respectively. Respiratory problems $(30.1 \%)$ was the most common reason leading to ICU admission. Patients with hematologic malignancies had higher Sequential Organ Failure Assessment (12 vs. 8, $\mathrm{P}<0.001$ ) and SAPS3 (71 vs. $69, P<0.001$ ) values and were more likely to be associated with chemotherapy, steroid therapy, and immunocompromised status versus patients with solid tumors. The use of inotropes/vasopressors, mechanical ventilation, and/or continuous renal replacement therapy was more frequently required in hematologic malignancy patients. Mortality rates in the ICU $(41.7 \%$ vs. $24.6 \%, \mathrm{P}<0.001)$ and hospital $(53.1 \%$ vs. $38.6 \%, \mathrm{P}=0.002)$ were higher in hematologic malignancy patients than in solid tumor patients.

Conclusions: Cancer patients accounted for one-third of all patients admitted to the studied ICUs in Korea. Clinical characteristics were different according to the type of malignancy. Patients with hematologic malignancies had a worse prognosis than did patients with solid tumor.

Key Words: cancer; critical care; epidemiology; hematologic neoplasm; mortality

\section{Original Article}

Received: April 20, 2018

Revised: July 16, 2018

Accepted: July 17, 2018

\section{Corresponding author}

Kyeongman Jeon

Department of Critical Care Medicine and Division of Pulmonary and Critical

Care Medicine, Department of Medicine, Samsung Medical Center, Sungkyunkwan University School of Medicine, 81 Irwonro, Gangnam-gu, Seoul 06351, Korea Tel: +82-2-3410-3429

Fax: +82-2-3410-6956

E-mail: kjeon@skku.edu

*The first two authors contributed equally to this study.

Copyright ( $\odot 2018$ The Korean Society of Critical Care Medicine

This is an Open Access article distributed under the terms of Creative Attributions Non-Commercial License (http:// creativecommons.org/li-censes/by-nc/4.0/) which permits unrestricted noncommercial use, distribution, and reproduction in any medium, provided the original work is properly cited. 


\section{INTRODUCTION}

The increase in the number of individuals with cancer and their improved prognosis has led to a growing demand for intensive care unit (ICU) management [1]. Even with these changes, some physicians consider ICU management in cancer patients to be a futile effort, and metastatic cancer is a common reason for refusal of ICU admission in practice [2]. Considering the disappointing survival rates of critically ill cancer patients in studies published in the 1980s and 1990s, triaging physicians' refusal ICU admission to cancer patients seems reasonable $[3,4]$.

However, recent investigations have demonstrated that advances in ICU management have led to an improvement of clinical outcomes in patients with and without cancer admitted to the ICU and suggested that critically ill cancer patients should not be excluded from the ICU only because they have cancer $[5,6]$. Domestic epidemiological data are needed to guide our practice in managing patients with cancer because there are geographic variations in the diagnosis of and type of cancer, but domestic data on clinical characteristics and outcomes in cancer patients are still limited [7]. Therefore, the present study was conducted to investigate the characteristics and clinical outcomes and predictors of mortality in critically ill cancer patients admitted to the ICU in Korea.

\section{MATERIALS AND METHODS}

\section{Study Design and Population}

This study used data from the Validation of Simplified Acute

\section{KEY MESSAGES}

- Cancer patients accounted for one-third of all patients admitted to the studied intensive care units in Korea.

- Clinical characteristics were different according to the type of malignancy.

- Patients with hematologic malignancies had a worse prognosis than did patients with solid tumor.

Physiology Score 3 (SAPS3) in Korean ICU (VSKI) study. The VSKI study, which is a nationwide, multicenter, and prospective study, was conducted by the Korean Study Group on Respiratory Failure between July 1, 2010 and January 31, 2011 to evaluate the prognostic performance of the SAPS3 in a large prospective cohort in Korea [8]. It included patients from 22 ICUs (14 medical, six surgical, and two multidisciplinary) in 15 tertiary or university-affiliated hospitals. Only the data from the index ICU admission were included.

A total of 5,063 patients were admitted to participating ICUs during the study period. Patients who were older than 18 years of age and diagnosed with solid or hematologic malignancies prior to admission to the ICU were eligible for inclusion in the present study. Among them, we excluded patients if they were electively admitted for postoperative care, transferred from other participating ICUs, or if they had no data available regarding hospital mortality (Figure 1). Patients were followed up until the time of death or hospital discharge. This study was approved by the relevant Institutional Review Board(s) of each participating hospital, and the requirement for informed

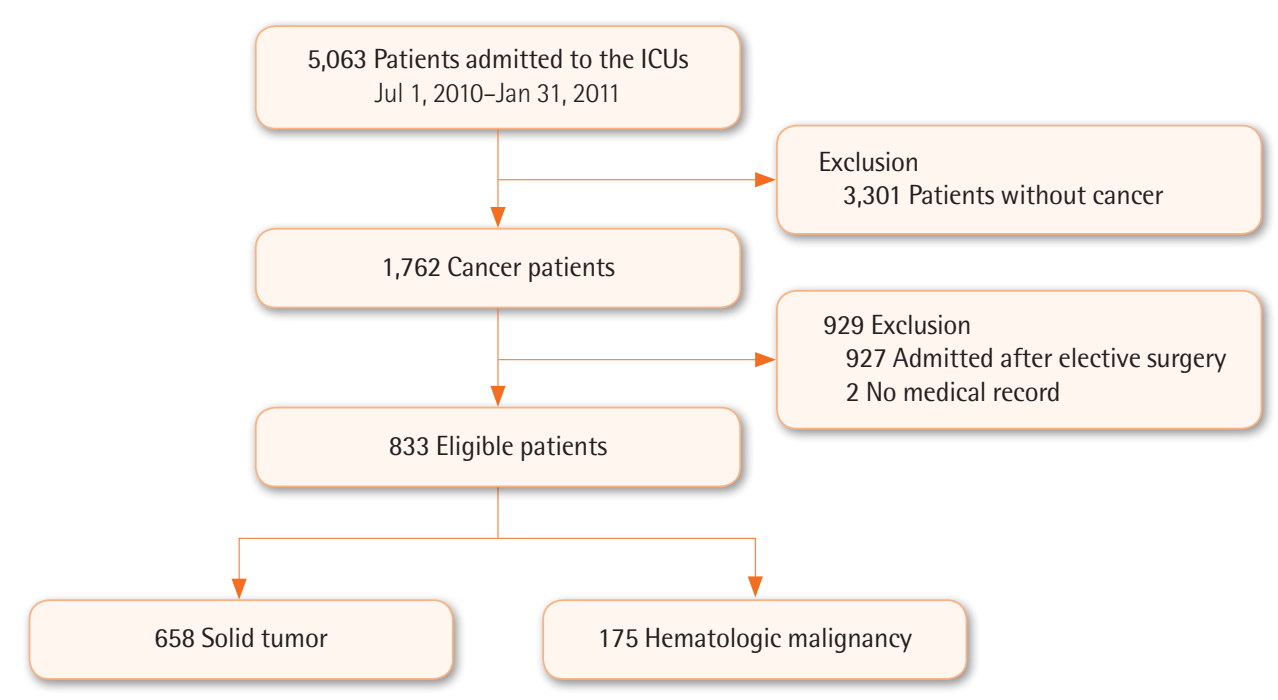

Figure 1. A schematic of study participant flow. ICU: intensive care unit. 
consent was waived because of the noninterventional nature of the study.

\section{Data Collection and Clinical Outcomes}

Patient data were collected using a web-based database. The definitions of variables used in the original SAPS3 model were used for this study [9]. We used the most abnormal set of data from the one hour prior to or after ICU admission to calculate SAPS3. The following data were sourced from the medical charts of the participants: demographic data; location prior to ICU admission; reason(s) for ICU admission; infection and surgical status at the time of ICU admission; laboratory data and physiologic measurements, which were collected within 1 hour before and 24 hours after ICU admission; and treatment(s) received during ICU stay. The severity of illness was assessed by the SAPS3 and Sequential Organ Failure Assessment (SOFA) score. The primary outcome in this study was hospital mortality. Secondary outcomes were ICU mortality, length of hospital stay, and length of ICU stay.

\section{Definition}

Cancer was categorized as solid or hematologic malignancy. Solid tumors were defined as cancer with proven distant (not regional lymph node) metastasis by surgery, computed tomography scan, or any other appropriate method. Hematologic malignancies were defined as tumors of the hematopoietic and lymphoid tissue including lymphoma, acute leukemia, and multiple myeloma. Infection was defined as the presence of a pathogenic microorganism in a sterile site and/or clinically suspected infection, plus the administration of antibiotics. Severe sepsis and septic shock were defined as sepsis associated with acute organ dysfunction and sepsis with acute circulatory failure characterized by persistent arterial hypotension (i.e., systolic arterial pressure $<90 \mathrm{mmHg}$, mean arterial pressure $<60 \mathrm{mmHg}$, or a reduction in systolic blood pressure $>40 \mathrm{mmHg}$ from baseline) despite adequate volume resuscitation, respectively [10]. Acute lung injury and acute respiratory distress syndrome were defined as arterial oxygen pressure to inspiratory oxygen fraction $\left(\mathrm{PaO}_{2} / \mathrm{FiO}_{2}\right)$ ratio $<300$ and $<200$, respectively, with the following criteria: acute onset, bilateral infiltrates on chest radiography, and pulmonary artery wedge pressure $<18 \mathrm{mmHg}$ or clinical evidence of left atrial hypertension. An unplanned ICU admission was defined as an admission planned less than 12 hours in advance or any unscheduled admission to the ICU that originated from the emergency department, general ward, operating room, or other location. Performance status was assigned a grade be- tween 0 and 4 according to the Eastern Cooperative Oncology Group performance status classification [11]. We used the definition of variables employed in the original SAPS3 model to define variables in this study [12].

\section{Statistical Analysis}

Data are presented as median and interquartile range (25th and 75th percentiles) for continuous variables and as numbers (percentages) for categorical variables. Data were compared using the Mann-Whitney U-test for continuous variables and the chi-square or Fisher exact test for categorical variables, respectively, where applicable. Logistic regression analyses were performed to identify risk factors for the prediction of mortality. Variables that appeared to be related in the univariate analysis with a P-value of less than 0.2 were introduced into multivariate regression models using a forward stepwise method. For all analyses, a two-tailed test with a Pvalue of less than 0.05 was considered to be statistically significant. We used the SPSS version 20.0 (IBM SPSS Corp., Armonk, NY, USA) for statistical analysis.

\section{RESULTS}

\section{Baseline Clinical Characteristics}

As shown in Figure 1, a total of 1,762 cancer patients were admitted to the ICUs and 833 of them were deemed eligible for analysis. The baseline characteristics of the 833 eligible patients finally included in the present study are described in Table 1. Of these, 554 (66.5\%) were male, and the median age was 63 years (range, 53 to 72 years). SOFA score and SAPS3 were 9 (range, 5 to 12) and 69 (range, 60 to 79), respectively. Unplanned admissions composed $74.4 \%$ of all ICU admissions. The most common reason for ICU admission was respiratory disease $(30.1 \%)$, followed by surveillance $(27.3 \%)$, cardiovascular disease (24.1\%), and digestive disease (5.4\%). About half of the patients included in this study had acute infection at the time of ICU admission, and most admissions were not related to surgery.

\section{Comparison of Baseline Characteristics According to Type of Malignancy}

Of the 833 patients, 658 (79\%) had solid tumors and $175(21 \%)$ had hematologic malignancies. The patients with solid tumors were typically older and more commonly male versus the patients with hematologic malignancies (Table 2). Performance status and comorbidities were similar between the two groups, except with regard to hypertension and liver cirrhosis. Patients 
Table 1. Baseline characteristics of cancer patients admitted to the ICU

\begin{tabular}{|c|c|}
\hline Characteristics & Value \\
\hline Age (yr) & $63(53-72)$ \\
\hline Male sex & $554(66.5)$ \\
\hline \multicolumn{2}{|l|}{ ECOG performance status ${ }^{\mathrm{a}}$} \\
\hline $0-1$ & $349(44.4)$ \\
\hline $2-4$ & $438(55.6)$ \\
\hline \multicolumn{2}{|l|}{ Comorbidity } \\
\hline Hypertension & $219(26.3)$ \\
\hline Diabetes & $153(18.4)$ \\
\hline Congestive heart failure & $30(3.6)$ \\
\hline Stroke & $35(4.2)$ \\
\hline Chronic lung disease & $14(1.7)$ \\
\hline Liver cirrhosis & $97(11.6)$ \\
\hline Chronic renal failure & $42(5.0)$ \\
\hline \multicolumn{2}{|l|}{ Severity of illness } \\
\hline SOFA & $9(5-12)$ \\
\hline SAPS3 & $69(60-79)$ \\
\hline \multicolumn{2}{|l|}{ Location before ICU admission } \\
\hline Emergency room & $377(45.3)$ \\
\hline General ward & $429(51.5)$ \\
\hline Other ICU & $20(2.4)$ \\
\hline Other & $7(0.8)$ \\
\hline \multicolumn{2}{|c|}{ Treatment history before ICU admission } \\
\hline Chemotherapy & $311(37.3)$ \\
\hline Radiotherapy & $105(12.6)$ \\
\hline Steroid & $29(3.5)$ \\
\hline Immune suppression status & $79(9.5)$ \\
\hline CPR before ICU admission & $44(5.3)$ \\
\hline Unplanned ICU admission & $620(74.4)$ \\
\hline \multicolumn{2}{|l|}{ Reason for admission } \\
\hline Surveillance & $228(27.3)$ \\
\hline Cardiovascular & $201(24.1)$ \\
\hline Respiratory & $251(30.1)$ \\
\hline Neurological & $29(3.5)$ \\
\hline Hepatic & $29(3.5)$ \\
\hline Digestive & $45(5.4)$ \\
\hline Renal & $9(1.1)$ \\
\hline Metabolic & $12(1.4)$ \\
\hline Hematological & $5(0.6)$ \\
\hline Other ${ }^{b}$ & $24(2.9)$ \\
\hline Acute infection at ICU admission & 427 (51.3) \\
\hline Severe sepsis/septic shock & $312(37.5)$ \\
\hline \multicolumn{2}{|l|}{ Surgical status at ICU admission } \\
\hline No surgery & $736(88.4)$ \\
\hline Emergent surgery & $97(11.6)$ \\
\hline
\end{tabular}

Values are presented as median (interquartile range) or number (\%). ICU: intensive care unit; ECOG: Eastern Cooperative Oncology Group: SOFA: Sequential Organ Failure Assessment; SAPS3: Simplified Acute Physiology Score 3; CPR: cardiopulmonary resuscitation.

aData were available for 787 patients; ${ }^{\text {In }}$ ncludes patients with spinal stenosis, trauma, urinary incontinence, and mood depression disorder. with hematologic malignancies had higher SOFA and SAPS3 values than did patients with solid tumors. The proportions of patients with a history of chemotherapy (57.1\% vs. $32.1 \%, \mathrm{P}<$ 0.001 ), steroid therapy ( $9.1 \%$ vs. $2.0 \%, \mathrm{P}<0.001)$, and compromised immune status $(17.7 \%$ vs. $7.3 \%, \mathrm{P}<0.001)$ were significantly higher in the hematologic malignancies group, while, conversely, the proportion of patients who had undergone radiotherapy ( $13.8 \%$ vs. $8.0 \%, \mathrm{P}=0.040)$ was higher in the solid tumor group. Unplanned ICUs admissions occurred more frequently among hematologic malignancy patients than among solid tumor patients. Respiratory ( $35.4 \%$ vs. $28.7 \%, \mathrm{P}=0.095)$ and cardiovascular ( $34.9 \%$ vs. $21.3 \%, \mathrm{P}<0.001$ ) problems were common causes of ICU admission in both groups, with the exception of admission for surveillance. More patients with hematologic cancer showed an acute infection status at the time of ICU admission. In addition, rates of severe sepsis/septic shock were significantly higher in patients with hematologic cancer as compared with those with solid cancer (57.1\% vs. $32.2 \%, \mathrm{P}<0.001)$.

\section{ICU Treatments}

The amount of total fluid administered within 24 hours (4,039 $\mathrm{ml}$ vs. 3,339 $\mathrm{ml}, \mathrm{P}<0.001$ ) was higher and the use of an inotrope/vasopressor ( $54.8 \%$ vs. $44.7 \%, \mathrm{P}=0.017$ ) was more prevalent, respectively, in patients with hematologic malignancies. In addition, hematologic malignancy patients more frequently required mechanical ventilation ( $46.9 \%$ vs. $33.3 \%, \mathrm{P}=0.001$ ) and continuous renal replacement therapy ( $17.6 \%$ vs. $9.5 \%$, $\mathrm{P}=0.004)$ than did solid tumor patients.

\section{Clinical Outcomes}

Overall, 235 patients $(28.2 \%$ ) died in the ICU, while 112 patients (13.4\%) died while hospitalized in other wards (Figure 2). Both ICU (41.7\% vs. $24.6 \%, \mathrm{P}<0.001)$ and hospital ( $53.1 \%$ vs. $38.6 \%$, $\mathrm{P}=0.002)$ mortality rates were significantly higher in patients with hematologic malignancies than in patients with solid tumors. Multivariable logistic regression analysis revealed that age, demonstration of performance status 2 through 4, mechanical ventilation usage, and SAPS3 in solid tumor patients (Table 3) and mechanical ventilation usage and SAPS3 in hematologic malignancy patients were significant prognostic predictors for hospital mortality (Table 3).

In the total patient cohort, ICU length of stay and hospital length of stay were 5 days (range, 3 to 10 days) and 20 days (range, 11 to 39 days), respectively. Although the ICU length of stay ( 5 days vs. 6 days, $\mathrm{P}=0.160$ ) was similar between patients with solid tumor and those with hematologic malignancies, 
Table 2. Baseline and treatment characteristics according to type of malignancy

\begin{tabular}{|c|c|c|c|}
\hline Variable & Solid tumor $(n=658)$ & Hematologic malignancies $(n=175)$ & P-value \\
\hline Age (yr) & $65(55-73)$ & $55(42-65)$ & 0.005 \\
\hline Male sex & $452(70.2)$ & $102(58.6)$ & 0.005 \\
\hline ECOG performance status ${ }^{a}$ & & & 0.928 \\
\hline $0-1$ & $271(44.2)$ & $78(44.6)$ & \\
\hline $2-4$ & $342(55.8)$ & $96(54.9)$ & \\
\hline \multicolumn{4}{|l|}{ Comorbidity (overlapped) } \\
\hline Hypertension & $191(29.0)$ & $28(16.0)$ & 0.001 \\
\hline Diabetes & $121(18.4)$ & $32(18.3)$ & $>0.999$ \\
\hline Congestive heart failure & $21(3.2)$ & $9(5.1)$ & 0.251 \\
\hline Stroke & $28(4.3)$ & $7(4.0)$ & $>0.999$ \\
\hline Chronic lung disease & $11(1.7)$ & $3(1.7)$ & $>0.999$ \\
\hline Liver cirrhosis & $93(14.1)$ & $4(2.3)$ & $<0.001$ \\
\hline Chronic renal failure & $32(4.9)$ & $10(5.7)$ & 0.703 \\
\hline \multicolumn{4}{|l|}{ Severity of illness } \\
\hline SOFA & $8(4-12)$ & $12(8-15)$ & $<0.001$ \\
\hline SAPS3 & $69(60-79)$ & $71(63-82)$ & $<0.001$ \\
\hline Location before ICU admission & & & $<0.001$ \\
\hline Emergency room & $323(49.1)$ & $54(30.9)$ & \\
\hline General ward & $314(47.7)$ & $115(65.7)$ & \\
\hline Other ICU & $15(2.3)$ & $5(2.9)$ & \\
\hline Other ${ }^{b}$ & $6(0.9)$ & $1(0.6)$ & \\
\hline Hospital days before ICU admission & $0(0-2)$ & $0(0-9)$ & 0.008 \\
\hline \multicolumn{4}{|l|}{ Treatment history before ICU admission } \\
\hline Chemotherapy & $211(32.1)$ & $100(57.1)$ & $<0.001$ \\
\hline Radiotherapy & $91(13.8)$ & $14(8.0)$ & 0.040 \\
\hline Steroid & $13(2.0)$ & $16(9.1)$ & $<0.001$ \\
\hline Immune suppression status & $48(7.3)$ & $31(17.7)$ & $<0.001$ \\
\hline CPR before ICU admission & $26(4.2)$ & $18(10.5)$ & 0.001 \\
\hline Unplanned ICU admission & $469(71.3)$ & $151(86.3)$ & $<0.001$ \\
\hline \multicolumn{4}{|l|}{ Reason for ICU admission } \\
\hline Surveillance & $190(28.9)$ & $38(21.7)$ & 0.070 \\
\hline Cardiovascular & $140(21.3)$ & $61(34.9)$ & $<0.001$ \\
\hline Digestive & $45(6.8)$ & 0 & 0.001 \\
\hline Hematological & $3(0.5)$ & $2(1.1)$ & 0.283 \\
\hline Hepatic failure & $29(4.4)$ & 0 & 0.004 \\
\hline Metabolic & $12(1.8)$ & 0 & 0.081 \\
\hline Neurological & $20(3.0)$ & $9(5.1)$ & 0.243 \\
\hline Renal & $7(1.1)$ & $2(1.1)$ & 1.000 \\
\hline Respiratory & $189(28.7)$ & $62(35.4)$ & 0.095 \\
\hline Other & $20(3.0)$ & $1(0.6)$ & 0.098 \\
\hline Acute infection at ICU admission & $298(45.3)$ & $129(73.7)$ & $<0.001$ \\
\hline Severe sepsis/septic shock & $212(32.2)$ & $100(57.1)$ & $<0.001$ \\
\hline
\end{tabular}


Table 2. Continued

\begin{tabular}{|c|c|c|c|}
\hline Variable & Solid tumor $(n=658)$ & Hematologic malignancies $(n=175)$ & P-value \\
\hline Surgical status at ICU admission & & & $<0.001$ \\
\hline No surgery & $566(86.0)$ & $170(97.1)$ & \\
\hline Emergent surgery & $92(14.0)$ & $5(2.9)$ & \\
\hline \multicolumn{4}{|l|}{ Initial laboratory variable } \\
\hline White blood cell $\left(\mathrm{mm}^{3}\right)$ & $9,750(5,320-15,460)$ & $3,640(250-9,850)$ & $<0.001$ \\
\hline Total bilirubin (mg/dl) & $0.9(0.6-2.1)$ & $1.1(0.7-2.3)$ & 0.297 \\
\hline Creatinine (mg/dl) & $1.0(0.7-1.6)$ & $1.1(0.7-1.8)$ & 0.381 \\
\hline Arterial pH & $7.39(7.30-7.45)$ & $7.40(7.30-7.46)$ & 0.159 \\
\hline Lactic acid (mmol/l) & $2.90(1.70-5.40)$ & $2.65(1.50-5.23)$ & 0.468 \\
\hline C-reactive protein (mg/dl) & $12.3(4.3-21.3)$ & $14.5(6.3-24.3)$ & 0.082 \\
\hline Procalcitonin (ng/ml) & $3.64(0.65-22.87)$ & $8.12(0.19-27.12)$ & 0.988 \\
\hline NT-proBNP (pg/ml) & $681(161-3039)$ & 965 (315-6070) & 0.019 \\
\hline \multicolumn{4}{|l|}{ Treatment } \\
\hline Total infused fluids within $24 \mathrm{hr}(\mathrm{ml})$ & $3,339(2,275-4,775)$ & $4,039(3,001-5,246)$ & $<0.001$ \\
\hline Inotrope/vasopressor within $24 \mathrm{hr}$ & $293(44.7)$ & $96(54.8)$ & 0.017 \\
\hline Norepinephrine & $251(38.4)$ & $84(48.8)$ & 0.012 \\
\hline Vasopressin & 53 (8.3) & $29(17.2)$ & 0.001 \\
\hline Dopamine & $64(10.0)$ & 19 (11.3) & 0.631 \\
\hline Dobutamine & $51(7.9)$ & $20(11.8)$ & 0.108 \\
\hline Epinephrine & $5(0.8)$ & $2(1.2)$ & 0.643 \\
\hline Mechanical ventilation & $219(33.3)$ & $82(46.9)$ & 0.001 \\
\hline Continuous renal replacement therapy & $60(9.5)$ & $30(17.6)$ & 0.004 \\
\hline
\end{tabular}

Values are presented as median (interquartile range) or number (\%).

ECOG: Eastern Cooperative Oncology Group; SOFA: Sequential Organ Failure Assessment; SAPS3: Simplified Acute Physiology Score 3; ICU: intensive care unit; CPR: cardiopulmonary resuscitation; NT-proBNP: N-terminal prohormone of brain natriuretic peptide.

aData were available for 787 patients; ${ }^{b}$ Includes patients with spinal stenosis, trauma, urinary incontinence, and mood depression disorder.

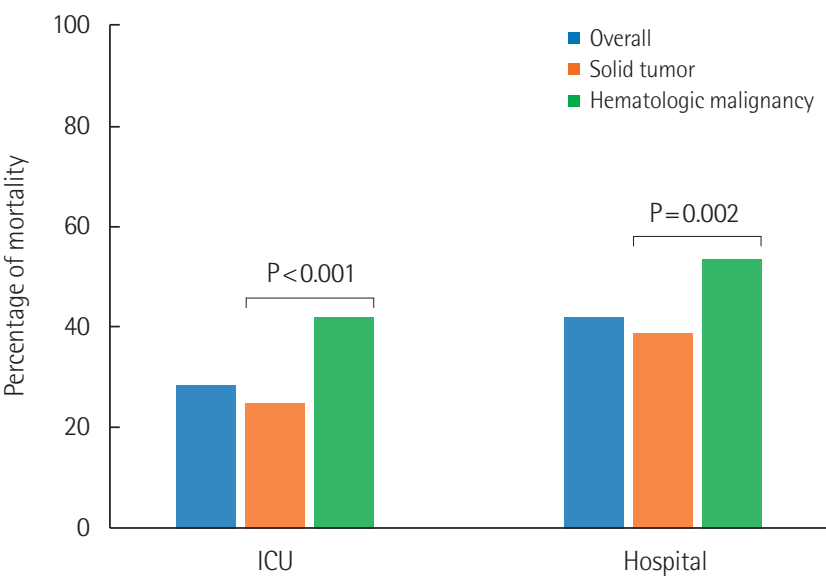

Figure 2. A comparison of intensive care unit (ICU) and hospital mortality.

the hospital length of stay (28 days vs. 19 days, $\mathrm{P}=0.001$ ) was noticeably longer in hematologic malignancy patients.
Table 3. Prognostic factors for hospital mortality

\begin{tabular}{lccr}
\hline Variable & $\begin{array}{c}\text { Adjusted } \\
\text { OR }\end{array}$ & 95\% Cl & P-value \\
\hline Patient with solid tumor & & & \\
$\quad$ Age & 0.96 & $0.93-0.99$ & 0.019 \\
ECOG performance status 2-4 & 2.63 & $1.29-5.37$ & 0.008 \\
Mechanical ventilation & 2.85 & $1.35-6.04$ & 0.006 \\
SAPS3 & 1.07 & $1.04-1.10$ & $<0.001$ \\
Patient with hematologic malignancies & & & \\
SAPS3 & 1.05 & $1.01-1.08$ & 0.006 \\
Mechanical ventilation & 2.41 & $1.05-5.55$ & 0.039 \\
\hline
\end{tabular}

OR: odds ratio; Cl: confidence interval; ECOG: Eastern Cooperative Oncology Group; SAPS3: Simplified Acute Physiology Score 3.

\section{DISCUSSION}

In this study, we investigated the epidemiology, characteristics, and clinical outcomes of critically ill cancer patients in 
Korea. Within our cohort, patients with cancer accounted for $34.8 \%$ of the total number of patients admitted to participating ICUs during the study period, and respiratory and cardiovascular diseases were two of the common causes of ICU admission in patients with malignancies. Our percentage of cancer patients admitted was relatively higher than those seen in the results of other previous studies that were conducted involving a mixed population, which ranged from $13.5 \%$ to $21.5 \%$ of overall ICU admissions $[5,13,14]$. Although it is difficult to compare our results to those of other investigations directly because our study did not examine the details of cancer, geographic variations in incidence and type of cancer may have an effect on the gap in the proportion of cancer patients admitted to the ICU [7].

Acute respiratory failure was identified as one of the most common medical conditions causing cancer patients to enter the ICU in previous studies as well as in our study $[13,15,16]$. The incidence of acute respiratory failure in cancer patients ranges from $10 \%$ to $50 \%$, and the risk of respiratory failure is higher in patients with hematologic malignancies, especially in patients who received allogeneic stem cell transplantation, as compared with in patients with solid tumor $[6,17,18]$. The most common cause of acute respiratory failure is pulmonary infection, but treatment-associated pulmonary toxicities, transfusion-related acute lung injury, lung involvement of underlying malignancy, and malignant airway obstruction also can cause a case of acute respiratory failure that requires ICU management [18].

Patients with hematologic malignancies have some clinical characteristics different from those of patients with solid tumor [13]. In our study, the proportion of patients who received chemotherapy and steroid therapy and that of patients with immunosuppression were higher, and observations of acute infection and severe sepsis/septic shock at the time of ICU admission were more frequent in patients with hematologic malignancies than in patients with solid tumor. In addition to a higher baseline SOFA score, the frequencies of vasopressor use, mechanical ventilation, and continuous renal replacement therapy during ICU treatment were all significantly higher in patients with hematologic malignancies. These findings are consistent with those of previous studies that showed that patients with hematologic malignancies are more likely to develop severe sepsis or septic shock in comparison with patients with solid tumor [13]. Neutropenia often occurs in hematologic malignancy patients due to an association with the underlying malignancy itself or chemotherapy; for example, in our study, the white blood cell counts in hematologic ma- lignancy patients were significantly lower than those in solid tumor patients, and it is known that neutropenic patients are more vulnerable to bacterial or fungal infections that have the potential to cause sepsis $[19,20]$.

Also, in regard to prognosis, solid tumor patients and hematologic malignancy patients showed different results. Although variations exist with regard to the type of cancer, patients with solid tumor have a global hospital mortality rate of $25 \%$ to $40 \%$, and some studies have demonstrated that mortality in this population is similar to that in ICU patients without cancer $[14,21]$. On the other hand, the hospital mortality rate of patients with hematologic malignancies is about $40 \%$ to $70 \%$, which is generally worse than that in solid tumor patients $[6,22]$. In particular, the mortality rate of patients with hematologic malignancies who receive hematopoietic stem cell transplantation is concerning, even in recent studies, at $63 \%$ to $75 \%[23,24]$. Hospital mortality rates in solid tumor patients and hematologic malignancy patients in our study were $38.6 \%$ and $53.1 \%$, respectively, which were similar to results reported in other countries.

SOFA score, multiple organ failure, the provision of organ support such as vasopressor use or mechanical ventilation, and allogeneic hematopoietic stem cell transplantation are known to be predictors of mortality in patients with cancer $[21,22,25,26]$. We also confirmed that higher SAPS3 value and mechanical ventilation support were associated with poor prognosis in both solid tumor and hematologic malignancy patients. Furthermore, age and premorbid performance status were independent prognostic factors for hospital mortality in patients with solid tumor. Some studies have demonstrated that advanced or recurrent cancer is a variable associated with poor outcomes, but others have suggested that cancer status generally does not affect the short-term outcomes of critically ill cancer patients $[25,27,28]$. Therefore, intensivists need to be careful when considering cancer status in deciding whether to pursue ICU admission for cancer patients.

Although our study investigated the clinical and treatment characteristics, outcomes, and variables associated with mortality in cancer patients admitted to the 22 medical and surgical ICUs in the Korea, there are several limitations that should be considered. First, our study did not record detailed data about the type, disease status, and treatment of cancer. Although some recent studies have suggested that the disease status of cancer does not adversely affect the short-term outcomes of cancer patients admitted to the ICU, progressive cancer or certain specific conditions, such as those that require mechanical ventilation for respiratory failure due to tumor involve- 
ment, are associated with poor prognosis [25]. Therefore, further studies that include additional information on disease status should be conducted to elucidate more accurately the characteristics of and to assess the clinical outcomes in critically ill cancer patients. Also, data about the code status at the time of ICU admission and change(s) in code status during ICU management, which may influence therapeutic decisions and mortality, were not collected. Finally, analyses comparing the cancer patients admitted to the ICU with cancer patients not admitted to the ICU were not performed, and we could not determine whether ICU management is beneficial in cancer patients with acute deterioration.

In conclusion, the proportion of patients with cancer is higher in Korea than in other countries, accounting for about onethird of all patients admitted to the ICU. The most common reason for ICU admission in nonsurgical cancer patients was respiratory problems. Patients with hematologic malignancies had higher severity scores and rates of organ support treatment and mortality than did those with solid tumor. Mechanical ventilation and SAPS3 were independent predictors of hospital mortality in both solid tumor and hematologic malignancy patients.

\section{CONFLICT OF INTEREST}

No potential conflict of interest relevant to this article was reported.

\section{ORCID}

Kyeongman Jeon https://orcid.org/0000-0002-4822-1772

\section{REFERENCES}

1. van Vliet M, Verburg IW, van den Boogaard M, de Keizer NF, Peek N, Blijlevens NM, et al. Trends in admission prevalence, illness severity and survival of haematological patients treated in Dutch intensive care units. Intensive Care Med 2014;40: 1275-84.

2. Garrouste-Orgeas M, Montuclard L, Timsit JF, Reignier J, Desmettre T, Karoubi P, et al. Predictors of intensive care unit refusal in French intensive care units: a multiple-center study. Crit Care Med 2005;33:750-5.

3. Schuster DP, Marion JM. Precedents for meaningful recovery during treatment in a medical intensive care unit: outcome in patients with hematologic malignancy. Am J Med 1983;75: 402-8.
4. Jackson SR, Tweeddale MG, Barnett MJ, Spinelli JJ, Sutherland HJ, Reece DE, et al. Admission of bone marrow transplant recipients to the intensive care unit: outcome, survival and prognostic factors. Bone Marrow Transplant 1998;21:697-704.

5. Soares M, Caruso P, Silva E, Teles JM, Lobo SM, Friedman G, et al. Characteristics and outcomes of patients with cancer requiring admission to intensive care units: a prospective multicenter study. Crit Care Med 2010;38:9-15.

6. Azoulay E, Mokart D, Pène F, Lambert J, Kouatchet A, Mayaux $\mathrm{J}$, et al. Outcomes of critically ill patients with hematologic malignancies: prospective multicenter data from France and Belgium. A groupe de recherche respiratoire en réanimation onco-hématologique study. J Clin Oncol 2013;31:2810-8.

7. Torre LA, Siegel RL, Ward EM, Jemal A. Global cancer incidence and mortality rates and trends: an update. Cancer Epidemiol Biomarkers Prev 2016;25:16-27.

8. Lim SY, Koh SO, Jeon K, Na S, Lim CM, Choi WI, et al. Validation of SAPS3 admission score and its customization for use in Korean intensive care unit patients: a prospective multicentre study. Respirology 2013;18:989-95.

9. Metnitz PG, Moreno RP, Almeida E, Jordan B, Bauer P, Campos RA, et al. SAPS 3: from evaluation of the patient to evaluation of the intensive care unit. Part 1: objectives, methods and cohort description. Intensive Care Med 2005;31:1336-44.

10. Levy MM, Fink MP, Marshall JC, Abraham E, Angus D, Cook D, et al. 2001 SCCM/ESICM/ACCP/ATS/SIS International Sepsis Definitions Conference. Crit Care Med 2003;31:1250-6.

11. Oken MM, Creech RH, Tormey DC, Horton J, Davis TE, McFadden ET, et al. Toxicity and response criteria of the Eastern Cooperative Oncology Group. Am J Clin Oncol 1982;5:649-55.

12. Moreno RP, Metnitz PG, Almeida E, Jordan B, Bauer P, Campos RA, et al. SAPS 3: from evaluation of the patient to evaluation of the intensive care unit. Part 2: development of a prognostic model for hospital mortality at ICU admission. Intensive Care Med 2005;31:1345-55.

13. Staudinger T, Stoiser B, Müllner M, Locker GJ, Laczika K, Knapp $\mathrm{S}$, et al. Outcome and prognostic factors in critically ill cancer patients admitted to the intensive care unit. Crit Care Med 2000;28:1322-8

14. Bos MM, de Keizer NF, Meynaar IA, Bakhshi-Raiez F, de Jonge E. Outcomes of cancer patients after unplanned admission to general intensive care units. Acta Oncol 2012;51:897-905.

15. Darmon M, Thiery G, Ciroldi M, de Miranda S, Galicier L, Raffoux E, et al. Intensive care in patients with newly diagnosed malignancies and a need for cancer chemotherapy. Crit Care Med 2005;33:2488-93.

16. Hawari FI, Nazer LH, Addassi A, Rimawi D, Jamal K. Predic- 
tors of ICU admission in patients with cancer and the related characteristics and outcomes: a 5-year registry-based study. Crit Care Med 2016;44:548-53.

17. Chi AK, Soubani AO, White AC, Miller KB. An update on pulmonary complications of hematopoietic stem cell transplantation. Chest 2013;144:1913-22.

18. Pastores SM, Voigt LP. Acute respiratory failure in the patient with cancer: diagnostic and management strategies. Crit Care Clin 2010;26:21-40.

19. Bhatt V, Saleem A. Review: drug-induced neutropenia. Pathophysiology, clinical features, and management. Ann Clin Lab Sci 2004;34:131-7.

20. Bodey GP, Buckley M, Sathe YS, Freireich EJ. Quantitative relationships between circulating leukocytes and infection in patients with acute leukemia. Ann Intern Med 1966;64:32840.

21. Puxty K, McLoone P, Quasim T, Sloan B, Kinsella J, Morrison DS. Risk of critical illness among patients with solid cancers: a population-based observational study. JAMA Oncol 2015; 1:1078-85.

22. Depuydt PO, Benoit DD, Vandewoude KH, Decruyenaere JM, Colardyn FA. Outcome in noninvasively and invasively ventilated hematologic patients with acute respiratory failure. Chest 2004;126:1299-306.

23. Platon L, Amigues L, Ceballos P, Fegueux N, Daubin D, Bes- nard N, et al. A reappraisal of ICU and long-term outcome of allogeneic hematopoietic stem cell transplantation patients and reassessment of prognosis factors: results of a 5-year cohort study (2009-2013). Bone Marrow Transplant 2016;51: 256-61.

24. Depuydt P, Kerre T, Noens L, Nollet J, Offner F, Decruyenaere $\mathrm{J}$, et al. Outcome in critically ill patients with allogeneic BM or peripheral haematopoietic SCT: a single-centre experience. Bone Marrow Transplant 2011;46:1186-91.

25. Azevedo LC, Caruso P, Silva UV, Torelly AP, Silva E, Rezende E, et al. Outcomes for patients with cancer admitted to the ICU requiring ventilatory support: results from a prospective multicenter study. Chest 2014;146:257-66.

26. Pène F, Aubron C, Azoulay E, Blot F, Thiéry G, Raynard B, et al. Outcome of critically ill allogeneic hematopoietic stemcell transplantation recipients: a reappraisal of indications for organ failure supports. J Clin Oncol 2006;24:643-9.

27. Soares M, Salluh JI, Spector N, Rocco JR. Characteristics and outcomes of cancer patients requiring mechanical ventilatory support for >24 hrs. Crit Care Med 2005;33:520-6.

28. Peigne V, Rusinová K, Karlin L, Darmon M, Fermand JP, Schlemmer B, et al. Continued survival gains in recent years among critically ill myeloma patients. Intensive Care Med 2009;35: 512-8. 